\title{
COIN BASED MOBILE CHARGER ON SOLAR ENERGY
}

Kalyani U. Chafle*1, B. M. Faruk ${ }^{2}$, R. S. Shrivas ${ }^{3}$, N.S.Sawarkar ${ }^{4}$

${ }^{*}$ Research Scholar, Department of Electronics and Telecommunication Engineering, Jawaharlal Darda Institute of Engineering \& Technology, Yavatmal, INDIA

${ }^{2,3}$ Assistant Professor, Department of Electronics and Telecommunication Engineering, Jawaharlal Darda Institute of Engineering \& Technology, Yavatmal, INDIA

${ }^{4}$ Assistant Professor, Department of Mechanical Engineering, Bhausaheb Mulak College of Engineering, Nagpur, INDIA

*Correspondence Author: kalyanichafle211@gmail.com

\begin{abstract}
:
The mobile phones are play's vital role in the present communication. The coin-based mobile battery charger developed in this paper for providing a unique service to the rural public where grid power is not available for partial/full daytime and a source of revenue for site providers. This can be quickly and easily installed outside any business premises. This type of charger will be very useful for the public people; many times the battery becomes flat in the middle of the conversation in particularly at inconvenient times when access to a standard charger isn't possible. The power supply for the charger is determined from solar power and current supply. When we put a coin, the coin detector detects the coin and the input is given to the controller. MOSFET acts as the switch in the circuit. This circuit can be placed in public places such as Bus stands, Railway stations, Hospitals.
\end{abstract}

Keywords:

MOSFET, Mobile Phones, Solar Panel, Battery Charger, Coin.

Cite This Article: Kalyani U. Chafle, B. M. Faruk, R. S. Shrivas, and N.S.Sawarkar, "Coin Based Mobile Charger on Solar Energy.” International Journal of Research - Granthaalayah, Vol. 3, No. 1(2015): 13-18. DOI: https://doi.org/10.29121/granthaalayah.v3.i1.2015.3046.

\section{INTRODUCTION}

The mobile phone market is a vast industry, and has spread into rural areas as an essential means of communication. While the urban populations use more sophisticated mobiles with good power batteries lasting for several days, the rural populations buy the pre-owned mobile phones that require charging frequently. Solar mobile charger is a device which can charge mobile phones using solar radiation. Its major component is a compact solar panel. This solar panel traps solar energy and produces an output voltage. But, since the light radiations falling on the solar panel can vary, the output voltage becomes unstable. For charging a mobile phone, stable voltage is required. So, to make the output voltage stable and regulated, a voltage regulator circuit along with the solar panel is used. Most of the mobile phones have computer connectivity via USB cable. USB port establishes 4 connection terminals. The connection terminals at the two extreme ends are the supply terminals. In a female USB connector (port via which we plug in USB devices to computer), 


\section{INTERNATIONAL JOURNAL of RESEARCH -GRANTHAALAYAH

these terminals carry 5V DC. When a mobile phone is connected to the USB port of a computer, it utilizes this $5 \mathrm{~V}$ supply to recharge battery. This feature is used in a solar mobile charger. It converts and regulates solar energy to $5 \mathrm{~V} \mathrm{DC}$ and the output will be available through the female USB connector. To this connector, we can easily connect a mobile phone via data.

Usually ordinary solar panel is always faces only in one direction. Because of this reason the solar panel may not get sufficient sun rays to work. Solar panel controller and power optimization is used in order to overcome this defect. The panel will rotate according to the readings read by the LDR. So it will utilize the full sun light to work \& power optimization is also done by using the LDR. It is mainly designed to control the solar panel automatically, maintains face of the solar panel towards the sun. This is done by controlling the mechanical movement of the solar panel.

\section{LITERATURE REVIEW}

A new type of charger designed for public people utilities. This type charger will be very useful for the public people; many times the battery becomes flat in the middle of conversation in particularly at inconvenient times when access to a standard is not possible. Therefore solar base mobile charger is more advantageous. The power supply for the charger is determined from solar power and current supply [1]. According to S. B. SHRIDEVI, describe coin base mobile charger using solar tracking system. In this research, the system is design for public in rural as well as semi urban. This is designed base on microcontroller that does the countdown time for a period for a 3 min. with LCD display showing the actual time left. During the time period a relay out is latch and finishing time in progress [2].

S. BHANU. PRATAP [3], Coin base based mobile charger is very useful in many developing countries where the current supply is not available for several hours on daily basis. In communication area mobile is essential for communication. They designed solar mobile charger for charging various manufacturers mobiles. It is used to help the people where the power supply is not available for some time daily. M.S. VARADARAJAN [5], the coin-based mobile battery charger is developed for providing a unique service to the rural public where grid power is not available for partial/full daytime and a source of revenue for site providers. The user has to plug the mobile phone into one of the adapters and insert a coin; the phone will then be given a micropulse for charging. It does not bring a mobile from 'dead' to fully charged state. The charging capacity of the mobile is designed with the help of pre-defined values. It is, of course, possible to continue charging the mobile by inserting more coins. This compact and lightweight product is designed to cater for the growing number of rural mobile users worldwide. A suitable microcontroller is programmed for all the controlling applications. The source for charging is obtained from direct power grid and solar energy in case of non-availability of grid power. 


\section{INTERNATIONAL JOURNAL of RESEARCH -GRANTHAALAYAH

\section{DESIGN AND WORKING PRINCIPLE}

The design of coin based mobile battery charger by using solar tracking system is based on the following assumptions:

a. Maximum solar energy is used for charging the lead acid battery inside the mobile battery charger to keep it charged fully all the time

b. The charging current is up to $4.5 \mathrm{AH} @ 6 \mathrm{vDC}$ and this takes care of the mobiles manufactured by Nokia, Sony-Ericson, Blackberry, HTC and others of first and second generation mobiles.

c. A single solar panel of size $635 \times 550 \times 38 \mathrm{~mm}, 37 \mathrm{WP}$ capable of supplying up to $2.0 \mathrm{amp}$ is used.

d. Provision to charge maximum 10 different types of mobiles is provided.

e. Insertion of a fixed coin size for charging

\subsection{SYSTEM STRUCTURAL DESIGN}

\subsubsection{SOLAR TRACKING SYSTEM}

The stepper motor is used for controlling mechanical movement of the solar panel. Power optimization is done by using LDR. Two LDR's has been placed on arch. So according to the sun movement LDR intensity can also be varied. Where the sun light intensity is more LDR intensity will be less and depending upon LDR intensities stepper motor will be rotated to the side where the LDR intensity is found to be less so that solar panel is also rotates. If the surrounding light is less than LDR reads maximum. According to the value of LDR the ADC shows the reading. The ADC will send this value to microcontroller. According to the value sent by the ADC the microcontroller glows the LED through relay. If the intensity of the light is more means all the LED array will be OFF. Depending upon the intensity of the light LED arrays will be switched $\mathrm{ON}$ or OFF.

\subsubsection{POWER SUPPLY}

The input to the circuit is applied from the regulated power supply as shown in fig. 3.1. The AC input i.e., $230 \mathrm{~V}$ from the mains supply is step down by the transformer to $12 \mathrm{~V}$ and is fed to a rectifier. The output obtained from the rectifier is a pulsating DC voltage. So in order to get a pure DC voltage, the output voltage from the rectifier is fed to a filter to remove any AC components present even after rectification. Now, this voltage is given to a voltage regulator to obtain a pure constant DC voltage.

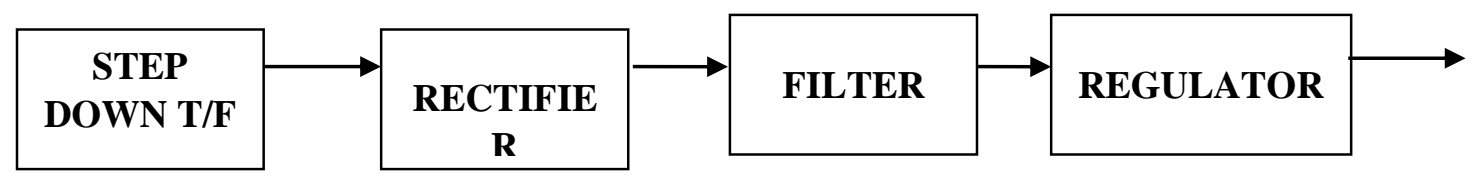

Figure 3.1 Power Supply 


\section{INTERNATIONAL JOURNAL of RESEARCH -GRANTHAALAYAH

\subsection{COIN BASED MOBILE CHARGER}

The basic block diagram of the coin based mobile charger is shown in fig.3.2.

\subsubsection{INPUT STAGE}

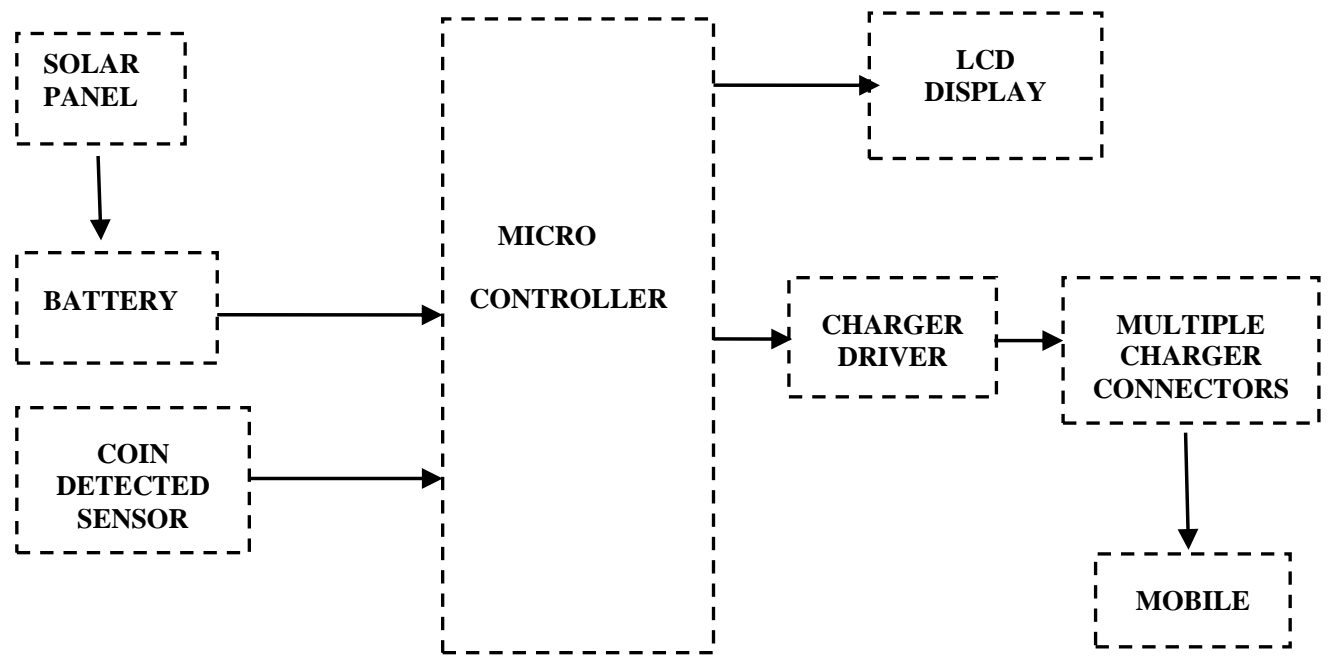

Figure 3.2 Block Diagram for Coin Based Mobile Charger

The mobile battery charger starts charging a mobile connected to it, when a coin is inserted at the coin insertion slot at the input stage. The type of coin and the size will be displayed at the LCD display for the user, so as to ensure correct coin insertion. Any other coin, if inserted in the slot will be returned to refund box. A mechanical slot is attached with electrical triggering in coin insertion slot, if the correct coin is inserted; it sends a pulse to the control unit authorizing the start of charging the mobile battery connected to the device. Then the coin insertion slot accepts the coin into the battery charging unit and start charging the mobile battery for a specific period controlled by the software of the microcontroller.

\subsubsection{CONTROLLER}

This section acts according to the input signal from the sensor circuit. Coin accepted or rejected is based on the diameter of the coin. This invokes microcontroller along with LCD interface displays the selection of mobile option if particular mobile is selected for charging the corresponding routine is activated and charge the mobile for a particular duration of time . When the routine completes, it indicates charge complete message through LCD display. Similarly the same procedure is followed for charging more than four different mobiles simultaneously.

\subsubsection{OUTPUT AND DISPLAY}

The LCD displays all the information to the customer as and when required. When the mobile battery is connected, it displays" Insert Coin". While charging it displays "Charging" and at the 


\section{INTERNATIONAL JOURNAL of RESEARCH -GRANTHAALAYAH

end of charging cycle it displays "Charge completed". For charging continuously the coin has to be inserted when the display shows "Charge Completed" The output has 10 terminals for connecting different types of mobile batteries and 7 of them are internally connected for charging mobile batteries of different make.

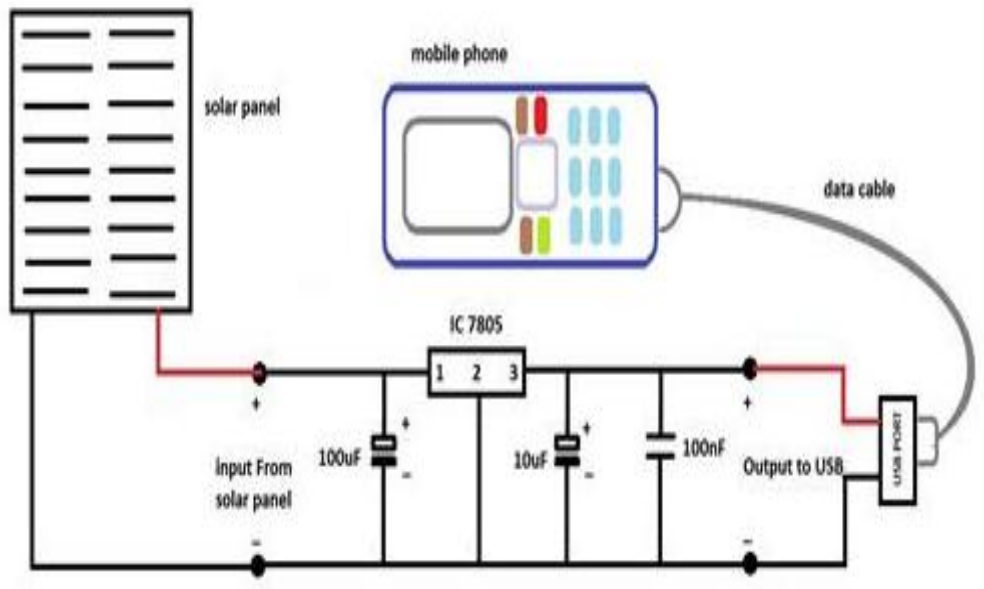

Figure 3.3 Final Schematic Representation of System [3]

All the components are soldered on a PCB. Final coin based mobile charger using solar tracking system is as shown in fig. 3.3.To test the regulator circuit, connect voltage between $8 \mathrm{~V}$ and $18 \mathrm{~V}$ to the input of voltage regulator. Now, measure the output. The output should be constant and it can be any value between $4.75 \mathrm{~V}$ and $5.25 \mathrm{~V}$. If so, the circuit is working properly. Next, just need to connect it to the USB port. Coin based mobile charger using solar tracking system is manufactured. Solder the positive output wire of the voltage regulator to the USB's positive. Similarly, connect the negative output of regulator to the negative of USB. The USB port must be fixed properly to the PCB. Next, connect the solar panel to the input of the voltage regulator (positive of solar panel to positive input of voltage regulator and negative of solar panel to negative input). Once everything is connected, measure the output voltage in open sun light. It should be around $5 \mathrm{~V}$. Now, connect the mobile phone and will see it charging.

\section{CONCLUSIONS}

The controller reads the program. At the same time the supply is given to the charger for a particular time period. The time period depends on the coding written in the controller. A multi pin charger is connected through the controller. By using the multi pin charger we may also use more than one mobile for charging. This compact and lightweight product is designed to cater for the growing number of rural mobile users worldwide. A suitable microcontroller is programmed for all the controlling applications. The source for charging is obtained from direct power grid and solar energy in case of non-availability of grid power. 


\section{INTERNATIONAL JOURNAL of RESEARCH -GRANTHAALAYAH \\ A knowledge Repository}

Science

In this work a method of charging mobile batteries of different manufacturer using solar power has been designed for rural and remote areas where the current supply is not at all available all the time. This charger is useful in today's life. Because now days the necessity of communication is very important, so every person having cell phone but every time we cannot carry charger with us. When we are going for long travel we may forget to carry cell phone charger.

\section{REFERENCES}

[1] M.S.Varadarajan., "Coin based Universal Mobile Battery Charger”, ISSN: 2250-3021 Volume 2, Issue 6, PP 1433- 1438, June 2012.

[2] K S.B.Sridevi, A. Sai Suneel. Nalini, “International Journal of Innovative Research in Science, Engineering and Technology”, ISSN: 2319-8753, ISO 3297: 2007 Vol. 3, Issue 2, PP.9603-9608, February 2014.

[3]T.Chandrashekhar,G.swaminadu,Ch.babu Rao, "Coin based mobile charger using Solar tracking system”, ISSN: 2278-909X, International Journal of Advanced Research in Electronics and Communication Engineering (IJARECE), Volume 2, Issue 9, PP 741-745, September 2013. [4] S.Banu Prathap, R.Priyanka, G.Guna, Dr.Sujatha, "Coin Based Cell Phone Charger", International Journal of Engineering Research \& Technology (IJERT) , ISSN: 2278-0181, Vol. 2 Issue 3, PP.1-4, March-2013.

[5] M.S.Varadarajan, “ Coin Based Universal Mobile Battery Charger”, IOSR Journal of Engineering (IOSRJEN), ISSN: 2250-3021, Volume 2, Issue 6, PP 1433-1438, June 2012. 